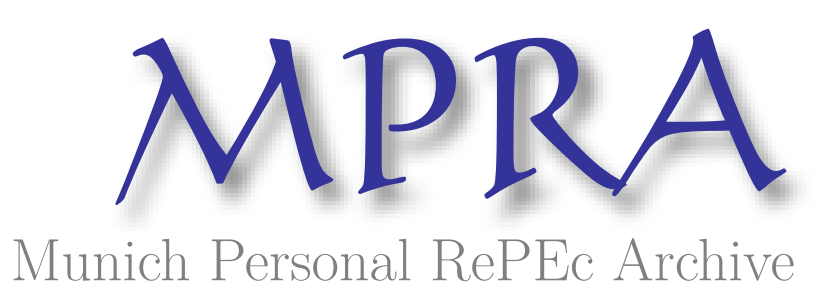

\title{
The Role of Noise in Alliance Formation and Collusion in Conflicts
}

Boudreau, James W. and Sanders, Shane and Shunda, Nicholas

University of Redlands

22 September 2017

Online at https://mpra.ub.uni-muenchen.de/81533/

MPRA Paper No. 81533, posted 23 Sep 2017 10:03 UTC 


\title{
The Role of Noise in Alliance Formation and Collusion in Conflicts
}

\author{
James W. Boudreau, Shane Sanders $\dagger$, and Nicholas Shunda
}

September 22, 2017

\begin{abstract}
Many real-world conflicts are to some extent determined randomly by noise. The way in which noise is modeled in contest success functions (CSFs) has has important implications both for the possibility of forming cooperative relationships as well as for the features of such relationships. In a one-shot conflict, we find that when noise is modeled as an exponential parameter in the CSF, there is a range of values for which an alliance between two parties can be beneficial, whereas that is not the case for an additive noise parameter. In an infinitely repeated conflict setting with additive noise, sustaining collusion via Nash reversion strategies is easier the more noise there is and more difficult the larger the contest's prize value, while an increase in the contest's number of players can make sustaining collusion either more or less difficult, all in marked contrast to the case of an exponential noise parameter. Which noise specification is appropriate is therefore an important consideration for modeling any conflict situation.

Journal of Economic Literature Classification Codes: C72, C73, D72, D74.

Keywords: Contests, conflict, alliance paradox, collusion, noise.
\end{abstract}

\footnotetext{
*Kennesaw State University, Email: jboudre5@kennesaw.edu.

†Syracuse University, Email: sdsander@syr.edu.

${ }^{\ddagger}$ University of Redlands, Email: nicholas_shunda@redlands.edu.
} 


\section{Introduction}

Conflict situations are often modeled as contests, in which players compete by making irrecoverable expenditures or costly efforts to increase their probability of winning a prize. ${ }^{1}$ In many cases, however, players' winning probabilities are determined not only by their expenditures, but also by additional factors of chance or noise. For example, a military conflict could be decided not only by the sizes of the countries' armies, but also by the geography and prevailing weather where the conflict takes place.

Another prominent aspect of conflicts is cooperation among competing parties, and whether or not such agreements are worthwhile or sustainable. Throughout history some warring factions have been able to ally with one another against rivals while others have fought on their own, all with varying degrees of success. In other circumstances, parties have managed to sustain collusive agreements of peace for extended periods. In this paper we consider the impact of incorporating noise into a contest model as one of the many factors that may influence whether or not conflicting parties can ally, cooperate, or collude.

The usual (one-shot) contest model features a finite set of players $I=$ $\{1, \ldots, n\}, n \geq 2$, with each player $i \in I$ spending an irrecoverable amount $x_{i}$ in an effort to win a conflict. Each player's probability of victory is determined by a contest success function (CSF), $p_{i}\left(x_{1}, \ldots, x_{n}\right)$. If all players assign a value of $v$ to the prize awarded to the winner of the contest, each player $i \in I$ then simultaneously maximizes

$$
\pi_{i}\left(x_{1}, \ldots, x_{n}\right)=p_{i}\left(x_{1}, \ldots, x_{n}\right) v-x_{i} .
$$

\footnotetext{
${ }^{1}$ Other applications of contest models include political lobbying, electoral competition, litigation, advertising competition, R\&D competition, and sporting competition.
} 
The most popular CSF is the Tullock (1980) CSF, which takes the form

$$
p_{i}\left(x_{1}, \ldots, x_{n}\right):= \begin{cases}\frac{x_{i}^{\gamma}}{x_{i}^{\gamma}+\sum_{j \neq i} x_{j}^{\gamma}} & \text { if } x_{i}^{\gamma}+\sum_{j \neq i} x_{j}^{\gamma} \neq 0 \\ \frac{1}{n} & \text { otherwise. }\end{cases}
$$

The exponent $0 \leq \gamma \leq 1$ measures the CSF's sensitivity to expenditures in determining winning probabilities. ${ }^{2}$ It is commonly referred to in contest theory literature as the CSF's discriminatory power following Hillman and Riley (1989), but can also be thought of as a noise parameter. For low levels of $\gamma$ (i.e., high levels of noise), winning probabilities do not vary much among players with small expenditure differences; in the limit as $\gamma \rightarrow 0$, the CSF is completely insensitive to expenditures and each player has a uniform $1 / n$ probability of winning no matter their expenditure choice. For high levels of $\gamma$ (i.e., low levels of noise), winning probabilities vary widely among players with small expenditure differences; in the limit as $\gamma \rightarrow \infty$, the CSF becomes the all-pay auction CSF in which the player making the highest expenditures wins with probability 1 .

An alternative CSF similar to the Tullock form but with an additive (rather than exponential) noise parameter was put forth by Amegashie (2006b). This CSF posits player $i$ 's probability of victory as

$$
p_{i}\left(x_{1}, \ldots, x_{n}\right):=\frac{x_{i}+\alpha}{x_{i}+\alpha+\sum_{j \neq i}\left(x_{j}+\alpha\right)}
$$

where $\alpha>0$ is the noise parameter. ${ }^{3}$ For the remainder of the paper, we will often refer to (2) simply as the additive noise CSF.

The two CSFs are similar, and each has desirable properties. The Tullock CSF's popularity in the literature stems from a variety of features, including

\footnotetext{
${ }^{2}$ The restriction on $\gamma$ is sufficient to ensure an interior pure-strategy Nash equilibrium.

${ }^{3}$ Dasgupta and Nti (1998) also use a similar CSF specification in their study of optimal contest design, but interpret their parameterization as the probability that the contest does not award the prize, which is more like the contests with the possibility of a draw studied by Blavatskyy (2010) and Jia (2012).
} 
its intuitive economic interpretation and the axiomatic properties provided by Skaperdas (1996). A stochastic foundation for its functional form is also provided by Jia (2008). The additive noise CSF preserves many, though not all (homogeneity of degree zero, for example), of the Tullock CSF's properties while, as Amegashie (2006b) notes, improving tractability in some cases. Rai and Sarin (2009) provide an axiomatic foundation and Jia (2012) provides a stochastic foundation for CSFs of the form in (2).

While the two CSFs are different in terms of what they allow a researcher to focus on, most importantly yielding solutions in terms of different parameters, the one-shot equilibria they admit are not all that different from one another qualitatively, especially when players are symmetric. When comparing the two models in the presence of opportunities for alliance formation or collusive arrangements, however, we find that they lead to very different results. In particular, in a one-shot conflict, a sufficient degree of exponential noise can make an alliance between two parties profitable relative to a non-cooperative state, while no such alliance exists under additive noise. This is due to the fact that only exponential noise allows the allies' expenditures to be sufficiently imperfectly substitutable in the allied CSF, mitigating free-riding incentives.

Perhaps more surprising is the difference between the two models when players attempt to sustain collusion in an infinitely repeated conflict. With the additive noise CSF, we show that an increase in the contest's degree of noise makes sustaining collusion easier, an increase in the contest's prize value makes sustaining collusion more difficult, and an increase in the contest's number of players can make sustaining collusion either more or less difficult. These results stand in rather stark contrast to the existing results on sustaining collusion with the Tullock CSF by Shaffer and Shogren (2008), who show that the prize value has no effect on collusion, while more noise and more players both make sustaining collusion more difficult.

The reason for these differences is the type of deviation made by defecting 
players in each case. With exponential noise a player can deviate from a collusive state of zero expenditure to win the prize with probability 1 with only an arbitrarily small amount of spending. With additive noise the optimal deviation is more complicated, since noise still to some extent determines the contest's outcome, even if all other players' spending levels are zero. This is also the reason why an increased number of players does not always make collusion more difficult, as it does in most other models.

In the following section, we consider a one-shot conflict with the possibility of alliance formation and how noise affects whether or not alliances are profitable for the allies themselves. We then develop a model of repeated conflict with noise, derive novel results on sustaining collusion via Nash reversion strategies with the additive noise CSF, and then compare those results to existing results on collusion in repeated conflicts with the Tullock CSF. A final section concludes the paper.

\section{Alliance Formation in One-Shot Conflicts with Noise}

What is the impact of noise on the prospect of alliance formation or collusive arrangements in conflict situations? We begin by considering a one-shot contest in which parties choose their expenditures simultaneously once and for all. In such a setting, some parties may choose to ally with one another, combining forces to take on another rival. For simplicity and for ease of comparison with other work in the alliance puzzle literature, in this section we confine our analysis to a three-party conflict, though it could be expanded to $n$ parties.

Konrad (2009) and Ke et al. (2013) consider a three-party conflict in which two parties are predesignated to ally with one another. Those two parties can be interpreted as perhaps compatible in some military or cultural way, while the third is not. Assuming parties 1 and 2 are the allies, the 
advantage to being in the alliance is that the allies' probabilities of victory are modified as

$$
p_{1}=p_{2}=\frac{x_{1}+x_{2}}{x_{1}+x_{2}+x_{3}} .
$$

The third party's CSF is the standard Tullock CSF with $\gamma=1$.

A downside to being in an alliance is that, in the event of a victory, the prize must be shared in some way. Ke, Konrad, and Morath (2013) consider two possibilities: that the prize may be shared equally between between the two parties, perhaps due to some prearranged binding contract, or fought over in a second-stage contest among the allies. We will primarily focus on the former case, so the value to winning the contest for each ally is simply $\frac{v}{2}$ rather than $v$, but will address results with the latter as well.

Regardless of which of the two sharing rules is used, taking first order conditions and solving for equilibrium expenditures and payoffs leads to what is known as the alliance puzzle. First, because the allied parties have identical first order conditions, only the sum of the alliance members' expenditures, and thus the sum of their expected payoffs are uniquely determined, not their individual values. Second, the combined allies' expenditures are less than the expenditure of either party on their own in the standard, unallied case, which leads the allies to have at best a combined payoff equal to that they would achieve if they were unallied. ${ }^{4}$ Specifically, for the case of equal prize division among allies:

(i.) $\left(x_{1}^{*}+x_{2}^{*}\right)=\frac{v}{9}$ while $x_{3}=\frac{2 v}{9}$,

(ii.) $p_{1}^{*}=p_{2}^{*}=\frac{1}{3}$ while $p_{3}^{*}=\frac{2}{3}$,

(iii.) and $\left(\pi_{1}^{*}+\pi_{2}^{*}\right)=\frac{2 v}{9}$ while $\pi_{3}=\frac{4 v}{9} \cdot{ }^{5}$

At best, the allies will end up with the same payoff they would have if they had not allied, and one may end up worse off. This is due in large

\footnotetext{
${ }^{4}$ In a standard contest with a Tullock CSF as in (1) with all parties maximizing their payoffs individually, $x_{i}^{*}=\frac{\gamma(n-1)}{n^{2}} v$ and $\pi_{i}^{*}=\frac{n-\gamma(n-1)}{n^{2}} v$ for all $i \in I$.

${ }^{5}$ Splitting the prize via second-stage intra-alliance conflict only harms the allies relative to the unallied party, as the additional conflict further dissipates the prize value for the allies.
} 
part to the free-riding effects caused by the perfect substitutability of allies' expenditures in the CSF, but also to the weakened expenditure incentives caused by splitting the prize.

With sufficient noise in the CSF, the alliance puzzle disappears. Note, however, that the noise must be of the exponential rather than the additive variety. Otherwise, if the allies' CSFs were modified to include noise as

$$
p_{1}=p_{2}=\frac{x_{1}+x_{2}+2 \alpha}{x_{1}+x_{2}+x_{3}+3 \alpha}
$$

with a complementary unallied $p_{3}$, the same results for the alliance paradox would persist. The allies' expenditures would remain perfectly substitutable in the CSF, so the free-riding effects would remain.

Suppose instead of being perfectly substitutable, the allies expenditures combine in the CSF as

$$
p_{1}=p_{2}=\frac{x_{1}^{\gamma}+x_{2}^{\gamma}}{x_{1}^{\gamma}+x_{2}^{\gamma}+x_{3}^{\gamma}}
$$

with $0<\gamma<1$, and $p_{3}$ the complementary probability. With equal prize division, the following first order conditions obtain:

$$
\begin{gathered}
\frac{\partial \pi}{\partial x_{1}}=\frac{x_{1}^{\gamma-1} x_{3}^{\gamma}}{\left(x_{1}^{\gamma}+x_{2}^{\gamma}+x_{3}^{\gamma}\right)^{2}} \frac{v}{2}-1=0, \\
\frac{\partial \pi}{\partial x_{2}}=\frac{x_{2}^{\gamma-1} x_{3}^{\gamma}}{\left(x_{1}^{\gamma}+x_{2}^{\gamma}+x_{3}^{\gamma}\right)^{2}} \frac{v}{2}-1=0,
\end{gathered}
$$

and

$$
\frac{\partial \pi}{\partial x_{3}}=\frac{x_{3}^{\gamma-1}\left(x_{1}^{\gamma}+x_{2}^{\gamma}\right)}{\left(x_{1}^{\gamma}+x_{2}^{\gamma}+x_{3}^{\gamma}\right)^{2}} \frac{v}{2}-1=0 .
$$

With three unique first order conditions, as opposed to only two in the perfectly substitutable case, it is possible to solve for unique expenditures and expected payoffs for all three parties. Along with the probabilities of victory, they are: 
(i*) $x_{1}^{*}=x_{2}^{*}=\frac{2^{2 \gamma-1} \gamma v}{\left(4^{\gamma}+2\right)^{2}}$ and $x_{3}^{*}=\frac{2^{2 \gamma+1} \gamma v}{\left(4^{\gamma}+2\right)^{2}}$,

(ii $i^{*}$.) $p_{1}=p_{2}=\frac{1}{1+2^{2 \gamma-1}}$ and $p_{3}=\frac{2^{2 \gamma-1}}{1+2^{2 \gamma-1}}$

(iii ${ }^{*}$.) $\pi_{1}=\pi_{2}=\frac{\left(2+2^{2 \gamma}-\gamma 2^{2 \gamma-1}\right)}{\left(2+2^{2 \gamma}\right)^{2}} v$ and $\pi_{3}=\left(\frac{2^{2 \gamma}}{2+2^{2 \gamma}}-\frac{2^{2 \gamma+1} \gamma}{\left(2^{2 \gamma}+2\right)^{2}}\right) v$.

Remark. The allies' collective action problem is more evident in $x_{1}^{*}$ and $x_{2}^{*}$ in $\left(i^{*}\right)$., as $\partial x_{1}^{*} / \partial \gamma<0$ and $\partial x_{2}^{*} / \partial \gamma<0$. The more sensitive the CSF is to the parties' efforts (i.e., the less noise there is), the worse is the incentive to free ride. More noise actually dampens the incentive to free ride, since ally expenditures become less substitutable.

The main result of this section comes from simply comparing the allies' payoffs in $\left(i_{i i}{ }^{*}\right.$.) with what they would achieve if all three parties simply maximized their payoffs individually with the CSF in (1). Both are decreasing in $\gamma$, or increasing in noise, because noise reduces equilibrium conflict expenditures. The allies' payoffs increase more quickly as noise increases ( $\gamma$ decreases) when they collude, however, since it alleviates their collective action problem while preserving some benefits of the allied CSF. There is therefore a threshold level of noise past which the allies are both unambiguously better off working together. Comparing payoffs and solving then leads to the following.

Proposition 1. For three-party contests with $0<0.245<\gamma$, parties who ally with a CSF as in (3) and divide their prize equally are unambiguously better off together than competing individually in a standard Tullock contest.

Sufficient noise in a conflict situation therefore makes alliances worthwhile when otherwise parties are better off fending for themselves. Again, however, this is only for the exponential noise specification, not the additive noise version.

Two additional features of alliance formation in conflicts with noise deserve mention. First, the alliance puzzle feature that remains is that the unallied party is made better off when two parties ally against it for any 
$0<\gamma \leq 1$, another result of the allies' reduced expenditures. For this reason, a corollary to the previous proposition is that sufficient noise, $0<\gamma<0.245$, makes it Pareto-improving for alliances to form in conflict situations when allies divide the prize equally. Second, if the allied parties do not share the prize in the event of victory, and instead divide it via a second-stage conflict, then alliances are never worthwhile for any $0<\gamma \leq 1$ as the prize value is too badly dissipated.

\section{Tacit Collusion in Repeated Conflicts with Noise}

Many real-world contests are also repeated. Repeated contests could provide players opportunities and incentives to collude by mutually refraining from competing with one another. If players are sufficiently patient (or, equivalently, believe the contest will repeat with a sufficiently high probability), then long-term collusion could dominate short-term opportunism when players use strategies with implicit threats to punish deviations from collusion. Continuing with the military conflict example, the long-lived nature of interactions among countries could provide them incentives to alter their military expenditures or reach other agreements that have them refrain from engaging in costly conflicts. Because there are many repeated contests with noise, gaining insight into how noise affects incentives for collusion in repeated contests is important.

Accordingly, we now analyze incentives for tacit collusion in an infinitely repeated contest with noise. We focus our analysis on the CSF with additive noise introduced by Amegashie (2006b), since Shaffer and Shogren (2008) have already performed a similar analysis for the Tullock CSF. ${ }^{6}$ Though our

\footnotetext{
${ }^{6}$ Other existing studies of contests with noise in the CSF are either one-shot (e.g., Cason et al. (2013), Wasser (2013), and Grossmann (2014)) or are repeated but do not analyze players' incentives for collusion (e.g., Eggert et al. (2011)).
} 
results on collusion in repeated conflicts with the additive noise CSF are of independent interest, comparison with the results from Shaffer and Shogren (2008) makes clear that the features of collusion in repeated conflicts strongly depend upon how noise enters the CSF.

If players are sufficiently patient, they can sustain maximal collusion (i.e., mutual refraining from conflict) by using Nash reversion strategies with either of the CSFs under consideration. With additive noise, we show that an increase in the contest's degree of noise makes sustaining collusion easier, while an increase in the contest's prize value makes sustaining collusion more difficult. The latter result is reminiscent of the well-known resource curse in which countries dependent upon wealth from natural resources like minerals and petroleum are more prone to violent conflict; for a review of the extensive resource curse literature, see Ross (2015). An increase in the contest's number of players can make sustaining collusion either more or less difficult. This last result for the additive noise CSF is perhaps the most interesting, since it means more parties being involved in a conflict does not always make collusion more difficult, contrary to most other economic models of competition.

In addition to its implications for conflict, this section contributes to a more general literature on collusion in repeated contests. The main message of this literature is that the long-lived nature of repeated contests can provide players incentives to collude, which typically leads to lowered contest expenditures. Yang (1993) and Leininger and Yang (1994) analyze contests in which players take turns choosing whether to increase or leave unchanged their current expenditures, which accumulate over the contest's horizon; when these alternating moves occur over an infinite horizon, a tit-for-tat-like strategy can enable players to keep their equilibrium expenditures low and possibly even minimal. Linster (1994) analyzes cooperative arrangements determined by the Nash bargaining solution when players' disagreement payoffs arise from reversion to Nash equilibrium play in an infinitely repeated 
contest. Amegashie (2006a) shows that increased prize value asymmetry between players makes sustaining collusion easier in an infinitely repeated contest. In an infinitely repeated game of investment with imperfect property rights, Amegashie (2011) shows that an equilibrium with overinvestment exists where the asset owner and the potential appropriator cooperate by not competing for the asset in a subsequent contest as long as the asset owner makes a transfer increasing in investment. Cheikbossian (2012) studies infinitely repeated contests between two groups of unequal size and shows that collusion (in the sense of a group overcoming its free-rider problem and increasing its expenditures) can be as easy to sustain in the larger group as it is in the smaller group. ${ }^{7}$

\subsection{The Repeated Conflict Model with Additive Noise CSF}

Each period $t=0,1,2, \ldots$, the $n$ players compete in a simultaneous-move contest to win a prize of value $v>0$ to each player. The stage games are the same as the one-shot contests described above, with each player $i \in I$ making irrecoverable expenditures $x_{i t} \geq 0$ to increase their winning probability $p_{i t}$, given by the additive noise CSF with parameter $\alpha$ from Amegashie (2006b):

$$
p_{i t}\left(x_{1 t}, \ldots, x_{n t}\right):=\frac{x_{i t}+\alpha}{x_{i t}+\alpha+\sum_{j \neq i}\left(x_{j t}+\alpha\right)} .
$$

As in the case of exponential noise, increasing the degree of noise in this CSF also has the effect of discouraging expenditures. Thus, we assume that $\alpha \in[0, \bar{\alpha})$ where $\bar{\alpha}:=(n-1) v / n^{2}$ so that the stage game's unique Nash equilibrium is interior; if instead $\alpha \geq \bar{\alpha}$, the stage game's unique Nash equi-

\footnotetext{
${ }^{7}$ There also exist a number of studies that analyze explicit collusion in one-shot contests (e.g., Alexeev and Leitzel $(1991,1996)$ and Huck et al. (2002)) and that develop models of infinitely repeated contests to analyze non-collusive behavior (e.g., Itaya and Sano (2003), Mehlum and Moene (2006), Krähmer (2007), Eggert et al. (2011), and Grossmann et al. (2011)).
} 
librium has each player making an expenditure of 0 and there exists no form of collusion yielding players a Pareto improvement thus making the analysis of incentives for collusion moot.

When players make expenditures $\left(x_{1 t}, \ldots, x_{n t}\right)$ in period $t$, the expected profits of player $i \in I$ in period $t$ are:

$$
\begin{aligned}
\pi_{i t}\left(x_{1 t}, \ldots, x_{n t}\right) & :=p_{i t}\left(x_{1 t}, \ldots, x_{n t}\right) v-x_{i t} \\
& =\frac{x_{i t}+\alpha}{x_{i t}+\alpha+\sum_{j \neq i}\left(x_{j t}+\alpha\right)} v-x_{i t} .
\end{aligned}
$$

Each player discounts streams of future profits to their present value according to the discount factor $\delta \in(0,1)$.

\subsection{Results on Collusion}

In the absence of collusion, we suppose that players make expenditures according to the stage game's Nash equilibrium. As Amegashie (2006b) shows, when $\alpha<(n-1) v / n^{2}$ the stage game has a unique Nash equilibrium in which each player makes expenditures

$$
x_{N}=\frac{n-1}{n^{2}} v-\alpha
$$

and earns expected profits

$$
\pi_{N}=\frac{v}{n^{2}}+\alpha
$$

each period. ${ }^{8}$

When $\alpha<(n-1) v / n^{2}$, players can improve upon the stage game's Nash

\footnotetext{
${ }^{8} \mathrm{It}$ is straightforward to show that the first derivative of (5) with respect to $x_{i t}$ is positive when $x_{j t}=0$ for all $j \in I \backslash\{i\}$ and $\alpha<(n-1) v / n^{2}$, ruling out all players making 0 expenditures as a Nash equilibrium. It is also straightforward to show that (5) is strictly concave in $x_{i t}$.
} 
equilibrium by collusion where each player makes an expenditure of

$$
x_{C}=0
$$

and earns expected profits

$$
\pi_{C}=\frac{v}{n}
$$

each period. We suppose that players use the following Nash reversion strategies of Friedman (1971) to sustain collusion tacitly as a subgame perfect Nash equilibrium of the infinitely repeated contest. ${ }^{9}$ Nash reversion strategies prescribe that each player $i \in I$

- makes an expenditure of $x_{C}=0$ in period $t=0$;

- makes an expenditure of $x_{C}=0$ in periods $t=1,2, \ldots$ as long as all players have made expenditures of $x_{C}=0$ in all periods to date; otherwise, the player makes an expenditure of $x_{N}=(n-1) v / n^{2}-\alpha$ forever.

As an alternative to Nash reversion strategies, we could analyze collusive behavior sustainable by the optimal punishment approach of Abreu (1986, 1988). Adopting such an approach would be preferable if Nash reversion strategies did not sustain maximal collusion because optimal punishments can support a wider range of collusive behavior in equilibrium. However, as we show below, since Nash reversion strategies do sustain maximal collusion, we opt to follow the Friedman (1971) approach.

The optimal deviation $x_{D}$ of a player $i \in I$ from the collusive arrangement above solves

$$
\max _{x_{i t}} \pi_{i t}\left(x_{i t}, 0, \ldots, 0\right)=\frac{x_{i t}+\alpha}{x_{i t}+n \alpha} v-x_{i t} .
$$

\footnotetext{
${ }^{9}$ Numerous studies of collusion in repeated contests follow a similar approach; see, for example, Linster (1994), Amegashie (2006a, 2011), Shaffer and Shogren (2008), and Cheikbossian (2012). Therefore, we adopt this approach so that our results on incentives for collusion are comparable to ones already existing in the literature.
} 
The first-order condition of (6) is

$$
\frac{(n-1) \alpha}{\left(x_{i t}+n \alpha\right)^{2}} v-1=0,{ }^{10}
$$

which is satisfied by

$$
\tilde{x}_{D}= \pm \sqrt{(n-1) \alpha v}-n \alpha,
$$

of which only $\tilde{x}_{D}=\sqrt{(n-1) \alpha v}-n \alpha>0$ when $\alpha<(n-1) v / n^{2}$. Therefore, the optimal deviation is

$$
x_{D}=\sqrt{(n-1) \alpha v}-n \alpha
$$

and earns expected profits of

$$
\pi_{D}=v-2 \sqrt{(n-1) \alpha v}+n \alpha
$$

Nash reversion strategies sustain collusion as a subgame perfect Nash equilibrium of the infinitely repeated contest if and only if the discounted profits from collusion exceed the discounted profits from deviation and reversion to the stage game's Nash equilibrium forever; that is, Nash reversion strategies sustain collusion if and only if

$$
\sum_{t=0}^{\infty} \delta^{t} \pi_{C} \geq \pi_{D}+\sum_{t=1}^{\infty} \delta^{t} \pi_{N}
$$

which simplifies to

$$
\frac{\pi_{C}}{1-\delta} \geq \pi_{D}+\frac{\delta}{1-\delta} \pi_{N}
$$

\footnotetext{
${ }^{10}$ It is straightforward to show that (6) is strictly concave in $x_{i t}$.
} 
or, in terms of a critical discount factor $\delta^{*}$,

$$
\begin{aligned}
\delta & \geq \frac{\pi_{D}-\pi_{C}}{\pi_{D}-\pi_{N}} \\
& =\frac{v-2 \sqrt{(n-1) \alpha v}+n \alpha-\frac{v}{n}}{v-2 \sqrt{(n-1) \alpha v}+n \alpha-\left(\frac{v}{n^{2}}+\alpha\right)}:=\delta^{*} .
\end{aligned}
$$

Note that $\delta^{*} \in(0,1)$ because $\pi_{D}>\pi_{C}$ holds if and only if $[(n-1) v / n-n \alpha]^{2}>$ 0 , which always holds, and $\pi_{C}>\pi_{N}$ holds if and only if $\alpha<(n-1) v / n^{2}$, which holds by assumption. Any factor increasing $\delta^{*}$ makes collusion more difficult to sustain and any factor decreasing $\delta^{*}$ makes collusion easier to sustain. The following proposition describes how $\delta^{*}$ varies with $\alpha, v$, and $n$.

Proposition 2. When players attempt to sustain maximal collusion by using Nash reversion strategies in an infinitely repeated contest with the contest success function in (4), (i) an increase in the contest's degree of noise makes sustaining collusion easier, (ii) an increase in the contest's prize value makes sustaining collusion more difficult, and (iii) an increase in the contest's number of players can make sustaining collusion either more or less difficult.

Proof. (i) Differentiating (7) with respect to $\alpha$, we have

$$
\begin{aligned}
\frac{\partial \delta^{*}}{\partial \alpha} & =\frac{-\frac{(n-1) v}{\sqrt{(n-1) \alpha v}}+n}{v-2 \sqrt{(n-1) \alpha v}+n \alpha-\left(\frac{v}{n^{2}}+\alpha\right)} \\
& -\frac{\left[v-2 \sqrt{(n-1) \alpha v}+n \alpha-\frac{v}{n}\right]\left[-\frac{(n-1) v}{\sqrt{(n-1) \alpha v}}+n-1\right]}{\left[v-2 \sqrt{(n-1) \alpha v}+n \alpha-\left(\frac{v}{n^{2}}+\alpha\right)\right]^{2}} \\
& =-\frac{\sqrt{(n-1) \alpha v}\{(n-1) v-n[2 \sqrt{(n-1) \alpha v}-n \alpha]\}}{\alpha\left[v-2 \sqrt{(n-1) \alpha v}+n \alpha-\left(\frac{v}{n^{2}}+\alpha\right)\right]^{2}}<0,
\end{aligned}
$$


which holds if and only if

$$
(n-1) v-n[2 \sqrt{(n-1) \alpha v}-n \alpha]>0,
$$

which holds if and only if

$$
\left[(n-1) v-n^{2} \alpha\right]^{2}>0
$$

which always holds.

(ii) Differentiating (7) with respect to $v$, we have

$$
\begin{aligned}
\frac{\partial \delta^{*}}{\partial v} & =\frac{1-\frac{(n-1) \alpha}{\sqrt{(n-1) \alpha v}}-\frac{1}{n}}{v-2 \sqrt{(n-1) \alpha v}+n \alpha-\left(\frac{v}{n^{2}}+\alpha\right)} \\
& -\frac{\left[v-2 \sqrt{(n-1) \alpha v}+n \alpha-\frac{v}{n}\right]\left[1-\frac{(n-1) \alpha}{\sqrt{(n-1) \alpha v}}-\frac{1}{n^{2}}\right]}{\left[v-2 \sqrt{(n-1) \alpha v}+n \alpha-\left(\frac{v}{n^{2}}+\alpha\right)\right]^{2}} \\
& =\frac{\sqrt{(n-1) \alpha v}\{(n-1) v-n[2 \sqrt{(n-1) \alpha v}-n \alpha]\}}{v\left[v-2 \sqrt{(n-1) \alpha v}+n \alpha-\left(\frac{v}{n^{2}}+\alpha\right)\right]^{2}}>0
\end{aligned}
$$

which holds if and only if

$$
(n-1) v-n[2 \sqrt{(n-1) \alpha v}-n \alpha]>0,
$$

which always holds, as we have shown above in (i). 


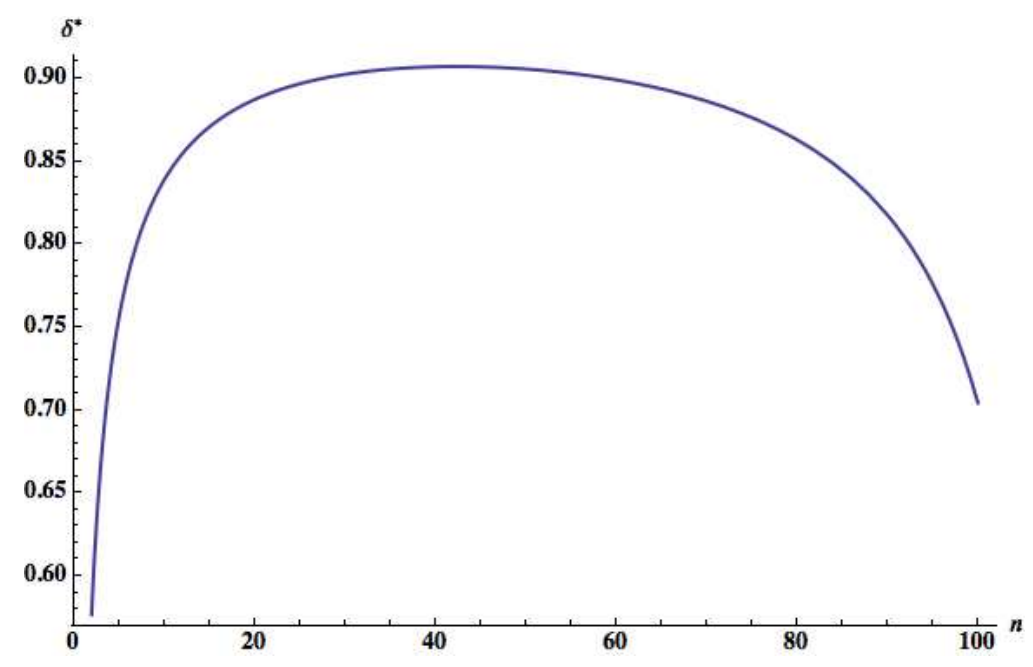

Figure 1: Critical Discount Factor Sustaining Collusion $(\alpha=0.9, v=100$, $n \in[2,100])$

(iii) Differentiating (7) with respect to $n$, we have

$$
\begin{aligned}
\frac{\partial \delta^{*}}{\partial n}= & \frac{-\frac{\alpha v}{\sqrt{(n-1) \alpha v}}+\alpha+\frac{v}{n^{2}}}{v-2 \sqrt{(n-1) \alpha v}+n \alpha-\left(\frac{v}{n^{2}}+\alpha\right)} \\
- & \frac{\left[v-2 \sqrt{(n-1) \alpha v}+n \alpha-\frac{v}{n}\right]\left[-\frac{\alpha v}{\sqrt{(n-1) \alpha v}}+\alpha+\frac{2 v}{n^{3}}\right]}{\left[v-2 \sqrt{(n-1) \alpha v}+n \alpha-\left(\frac{v}{n^{2}}+\alpha\right)\right]^{2}} \gtrless 0 .
\end{aligned}
$$

Figure 1 illustrates the nonmonotonic relationship between $n$ and $\delta^{*}$ by graphing (4) for $\alpha=0.9, v=100$, and $n \in[2,100]$. Figure 1 shows that an increase in $n$ initially makes collusion more difficult to sustain and eventually makes collusion easier to sustain.

The properties of $\delta^{*}$ are fairly intuitive. An increase in $\alpha$ decreases $\pi_{D}$, decreasing incentives to deviate from collusion, while it increases $\pi_{N}$, increasing deviation incentives because of the less severe Nash reversion punishment; the former effect dominates, thus an increase in $\alpha$ makes sustaining collusion 
easier. An increase in $v$ has three effects on $\delta^{*}$ : it increases $\pi_{D}$ and $\pi_{N}$, both of which decrease incentives to deviate from collusion, and it increases $\pi_{C}$, increasing incentives for collusion; the first two effects dominate, thus an increase in $v$ makes sustaining collusion more difficult. An increase in $n$ also has three effects on $\delta^{*}$ : it decreases $\pi_{D}$ and $\pi_{N}$, both of which decrease incentives to deviate from collusion, and it decreases $\pi_{C}$, decreasing incentives for collusion; which of the three effects dominate depends upon the levels of $\alpha, v$, and $n$, thus an increase in $n$ can make sustaining collusion either more or less difficult.

\subsection{Comparing Models of Repeated Conflicts with Noise}

Our results on the factors affecting the sustainability of collusion with additive noise differ markedly from the closely related analysis of Shaffer and Shogren (2008), who analyze incentives for collusion in an infinitely repeated contest with the Tullock CSF. When players attempt to sustain collusion by using Nash reversion strategies, Shaffer and Shogren (2008) show that a decrease in $\gamma$ (i.e., an increase in the level of noise in the contest) makes sustaining collusion more difficult by making the Nash reversion punishment less severe. ${ }^{11}$ Shaffer and Shogren (2008) also show that an increase in the contest's prize value does not affect the sustainability of collusion and that an increase in contest's number of players makes sustaining collusion more difficult. Broadly speaking, our results differ from one another because of the nature of players' deviations from collusion.

In the case of the Tullock CSF, as in Shaffer and Shogren (2008), each player's optimal deviation from collusion involves making an infinitesimally small expenditure and winning the contest with probability 1 because the Tullock CSF lacks noise in this case. This means $\pi_{D} \approx v, \pi_{C}=\frac{v}{n}$ as before, and $\pi_{N}=\frac{n-\gamma(n-1)}{n^{2}} v$ is the well-known Nash equilibrium for the one-

\footnotetext{
${ }^{11}$ Shaffer and Shogren (2008) analyze the critical discount rate $\left(r^{*}\right)$ sustaining collusion, which relates to the critical discount factor $\left(\delta^{*}\right)$ we analyze as $\delta^{*}=1 /\left(1+r^{*}\right)$.
} 
shot Tullock contest. Importantly, then, the only payoff affected by noise is the Nash equilibrium payoff, the punishment for defection, which increases as noise increases (i.e., as $\gamma$ decreases). More noise therefore makes the punishment for deviating less severe, making collusion more difficult. The collusive, deviation, and Nash equilibrium payoffs are all proportional to $v$, so it drops out of the threshold $\delta^{*}$ completely and has no impact on collusion, and the dominant impact of an increase in $n$ is to decrease the collusive payoff, making collusion harder to sustain. Specifically, for the Tullock CSF we can calculate the threshold

$$
\delta^{*}=\frac{n^{2}-n}{n^{2}-n+\gamma(n-1)},
$$

which is much simpler than the $\delta^{*}$ in the case of additive noise presented in the previous subsection.

By contrast, the additive noise CSF always has noise, whether players make expenditures or not, and thus each player's optimal deviation from collusion is more complex. Simply making some positive expenditure when all other players make 0 expenditures does not guarantee that a player wins the contest with probability 1 . The more complicated nature of the optimal deviation, and in turn $\pi_{D}$, is then what leads to the different results for the additive noise model when it comes to sustaining collusion, since $\pi_{D}$ is nonlinear in all three of the parameters of interest. The collusive payoffs are the same in both cases, and the Nash equilibrium payoffs are qualitatively very similar, both increasing in noise and decreasing in $n$. The fact that more noise, a larger prize, and more players have such different impacts on the ability to sustain collusion in a repeated conflict with additive noise, as compared to exponential noise, is therefore due to the payoff to defection, and how those factors impact that payoff in each case. 


\section{Conclusion}

In this paper, we develop and study models of one-shot and repeated conflicts whose outcomes are to some extent determined by noise. In one-shot conflicts where players have the possibility of forming alliances, exponential noise in the Tullock CSF can make alliance formation profitable to allies and overcome the alliance puzzle while additive noise in the CSF from Amegashie (2006a) cannot. In repeated conflicts with additive noise and the possibility of collusion, we show that sustaining collusion is easier the more noise there is and more difficult the larger the contest's prize value, while an increase in the contest's number of players can make sustaining collusion either more or less difficult, all in marked contrast to the exponential noise case analyzed by Shaffer and Shogren (2008). Though we make no claim as to which form of noise in conflicts is more realistic, our results clearly demonstrate that the form of noise present in a conflict has important implications both for the possibility of forming cooperative relationships as well as for the features of such relationships.

Thinking in terms of what our results mean for conflict situations, it seems reasonable that the degree of randomness present in any situation may prevent players' expenditures from impacting their probability of victory precisely. In addition to having the effect of lowering individual spending in a standard contest, we have shown that the presence of such imperfections can actually make alliances between warring parties worthwhile, since the imprecision makes their spending less substitutable, and thus more valuable to one another. Having more precise control over events would actually make it more difficult for the parties to trust one another due to stronger freeriding incentives. This suggests that military alliances might be less common if the conflict outcomes were made less random through, for example, the deployment of enhanced military technologies.

Does randomness disappear if players refrain from conflict spending? This question proves to be important in a repeated setting. If players in a re- 
peated conflict situation have achieved a peaceful arrangement, the incentive to break the peace is very different if one player can win the prize with certainty with an arbitrarily small effort, as opposed to a situation in which the now one-sided conflict's outcome is to some extent random. If more players means a larger amount of extant randomness ( $n \alpha$ in the denominator of the additive noise CSF), for example, then a larger number of players actually makes a collusive outcome easier to sustain. This result, which is fairly unusual, is due to the fact that there is more randomness to overcome for any would-be defector. In conflicts with additive noise, growth in the number of players in conflict has the effect, among others, of amplifying the amount of noise determining the conflicts outcome. Since we have demonstrated that an increase in noise makes sustaining collusion relatively easier, it stands to reason that an increase in the number of players can in some cases have the same overall effect. 


\section{References}

Abreu, D. (1986). Extremal Equilibria of Oligopolistic Supergames. Journal of Economic Theory, 39(1), 191-225.

Abreu, D. (1988). On the Theory of Infinitely Repeated Games with Discounting. Econometrica, 56(2), 383-396.

Alexeev, M., \& Leitzel, J. (1991). Collusion and Rent-Seeking. Public Choice, $69(3), 241-252$.

Alexeev, M., \& Leitzel, J. (1996). Rent Shrinking. Southern Economic Journal, 62(3), 620-626.

Amegashie, J. A. (2006a). Asymmetry and Collusion in Infinitely Repeated Contests. Working Paper, University of Guelph.

Amegashie, J. A. (2006b). A Contest Success Function with a Tractable Noise Parameter. Public Choice, 126(1-2), 135-144.

Amegashie, J. A. (2011). Incomplete Property Rights and Overinvestment. Social Choice and Welfare, 37(1), 81-95.

Blavatskyy, P. R. (2010). Contest Success Function with the Possibility of a Draw: Axiomatization. Journal of Mathematical Economics, 46(2), $267-276$.

Cason, T. N., Masters, W. A., \& Sheremeta, R. M. (2013). Winner-Take-All and Proportional-Prize Contests: Theory and Experimental Results. Working Paper, Case Western Reserve University.

Cheikbossian, G. (2012). The Collective Action Problem: Within-Group Cooperation and Between-Group Competition in a Repeated RentSeeking Game. Games and Economic Behavior, $74(1), 68-82$. 
Dasgupta, A., \& Nti, K. O. (1998). Designing an Optimal Contest. European Journal of Political Economy, 14(4), 587-603.

Eggert, W., Itaya, J., \& Mino, K. (2011). A Dynamic Model of Conflict and Appropriation. Journal of Economic Behavior 83 Organization, $78(1-2), 167-182$.

Friedman, J. W. (1971). A Non-Cooperative Equilibrium for Supergames. Review of Economic Studies, 38(1), 1-12.

Grossmann, M. (2014). Uncertain Contest Success Function. European Journal of Political Economy, 33, 134-148.

Grossmann, M., Lang, M., \& Dietl, H. (2011). Transitional Dynamics in a Tullock Contest with a General Cost Function. B.E. Journal of Theoretical Economics, 11(1), Article 17.

Hillman, A. L., \& Riley, J. G. (1989). Politically Contestable Rents and Transfers. Economics \& Politics, 1(1), 17-39.

Huck, S., Konrad, K. A., \& Müller, W. (2002). Merger and Collusion in Contests. Journal of Institutional and Theoretical Economics, 158(4), $563-575$.

Itaya, J., \& Sano, H. (2003). Exit from Rent-Seeking Contests. Japanese Economic Review, 54 (2), 218-228.

Jia, H. (2012). Contests with the Probability of a Draw: A Stochastic Foundation. Economic Record, 88(282), 391-406.

Ke, C., Konrad, K. A., \& Morath, F. (2013). Brothers in arms-An experiment on the alliance puzzle. Games and Economic Behavior, 77(1), 61-76.

Konrad, K. A. (2009). Strategy and Dynamics in Contests. Oxford University Press, New York. 
Krähmer, D. (2007). Equilibrium Learning in Simple Contests. Games and Economic Behavior, 59(1), 105-131.

Leininger, W., \& Yang, C. (1994). Dynamic Rent-Seeking Games. Games and Economic Behavior, 7(3), 406-427.

Linster, B. G. (1994). Cooperative Rent-Seeking. Public Choice, 81(1-2), 23-34.

Mehlum, H., \& Moene, K. (2006). Fighting Against the Odds. Economics of Governance, 7(1), 75-87.

Rai, B. K., \& Sarin, R. (2009). Generalized Contest Success Functions. Economic Theory, 40(1), 139-149.

Shaffer, S., \& Shogren, J. (2008). Infinitely Repeated Contests: How Strategic Interaction Affects the Efficiency of Governance. Regulation $\mathscr{E}$ Governance, 2(2), 234-252.

Skaperdas, S. (1996). Contest Success Functions. Economic Theory, 7(2), 283-290.

Tullock, G. (1980). Efficient Rent Seeking. In Buchanan, J., Tullock, G., \& Tollison, R. (Eds.), Toward a Theory of the Rent-Seeking Society, pp. 97-112. Texas A\&M University Press.

Wasser, C. (2013). Incomplete Information in Rent-Seeking Contests. Economic Theory, 53(1), 239-268.

Yang, C. (1993). Cooperation by Credible Threats: On the Social Costs of Transfer Contests Under Uncertainty. Journal of Institutional and Theoretical Economics, 149(3), 559-578. 